\title{
Reduction of Fibrillation of Lyocell Fiber with Cellulose- $g$-Poly(vinyl alcohol) Copolymer
}

\author{
Kyung Yul LiM, Yun Jeong SEONG, and Byoung Chul KIM ${ }^{\dagger}$ \\ Division of Chemical Engineering, Hanyang University, 17 Haengdang, Seongdong, Seoul 133-791, Korea
}

(Received October 19, 2002; Accepted April 25, 2003)

\begin{abstract}
Cellulose- $g$-poly(vinyl alcohol) (cellulose- $g$-PVA) copolymers, which contain vinyl alcohol(VA) content 13,36 , and $47 \mathrm{wt} \%$, were prepared, and the effects of introducing the copolymers on the fibrillation of lyocell fibers were investigated. Five wt $\%$ copolymer to cellulose was added to $13 \mathrm{wt} \%$ cellulose solution in $N$-methyl morpholine $N$-oxide (NMMO) monohydrate and lyocell fibers were produced by dry jet-wet spinning of cellulose/cellulose- $g$-PVA blend solutions. Variation of VA content had little effect on crystal structure and mechanical properties of lyocell fibers. However, the birefringence of the fibers decreased with increasing VA content. In the case of lyocell fibers containing the copolymer with VA content $47 \mathrm{wt} \%$, microfibril structure in the cross-section of fractured fibers disappeared. The VA group of the copolymers thus interrupts the orientation of cellulose chains due to strong hydrogen bonding. Fibers containing the copolymers gave less fibrillation than lyocell fibers, which became more noticeable at higher VA content. Addition of copolymers proved effective for the control of fibrillation of lyocell fiber.
\end{abstract}

KEY WORDS Lyocell Fiber / Fibrillation / Polyvinyl Alcohol / Cellulose Graft Copolymer /

Lyocell fibers produced by cellulose solution in $\mathrm{N}$ methyl morpholine $N$-oxide (NMMO) hydrate attracts much attention owing to better drape and mechanical properties in wet state than other cellulose fibers. ${ }^{1-8}$ NMMO solvent-spun process is environmentally benign, and the nontoxic solvent, NMMO, can be almost totally recycled.

Lyocell fibers spun through dry jet-wet spinning system have well-oriented structure, frequently leading to undesirable fibrillation under wet abrasion. ${ }^{9-11}$ Lenz et $a l .{ }^{12,13}$ reported the relation between orientation and fibril structure of lyocell fibers. Higher orientation is accompanied by higher fibrillation because of weak lateral cohesion between crystal regions. Although fibrillation gives peach skin touch it gives rise to poor launderability of textile products and unexpected problems during weaving, dyeing and finishing. Research has been carried out to effectively control of the fibrillation of lyocell fibers, such as finishing by enzyme degradation and surface coating, changing spinning parameters, and putting cross-linking agents in polymer solution. $^{14-16}$

We controlled fibrillation of lyocell fibers by adding cellulose copolymer grafted by vinyl alcohol monomer (cellulose-g-PVA), the cellulose solution in NMMO monohydrate. The alcohol groups of the grafted PVA make hydrogen bonds with cellulose to reduce the fibrillation of lyocell fiber because hydrogen bonds may improve the lateral cohesion of cellulose chains by acting as physical cross-linkage points.
This study investigates the effects of cellulose- $g$-PVA copolymer on the suppression of fibrillation of lyocell fibers. Copolymers with different VA content were prepared by saponification of the corresponding precursor copolymers in which vinyl acetate (VAC) was grafted onto the cellulose backbone. The modified lyocell fibers were prepared by spinning a solution of the mixture of cellulose and copolymer in NMMO monohydrate. The effect of introducing VA into the lyocell fiber is discussed in terms of crystal structure, morphology and fibrillation.

\section{EXPERIMENTAL}

\section{Materials}

$\alpha$-Cellulose (Sigma Co.) with weight- average degree of polymerization 800 was used after dried in a vacuum oven at $60^{\circ} \mathrm{C}$. VAC monomer (Kanto chemical Co.) was washed with $1 \%$ solution of $\mathrm{NaOH}$, and dried with $\mathrm{CaCl}_{2}$. Cerium ammonium nitrate $(\mathrm{CAN}$, Aldrich Co., $99<\%$ ) was used as an initiator of cellulose. NMMO monohydrate solution was obtained by reduced pressure distillation of $49.6 \mathrm{wt} \%$ aqueous NMMO (Enka Co.) solution. n-Propyl gallate (PG, Aldrich Co.) was used as an antioxidant of cellulose.

\section{Preparation of Cellulose-g-PVA Copolymer}

Cellulose-g-PVA copolymers with different PVA content were prepared by saponification of the corresponding cellulose- $g$-PVAC copolymers. Cellulose- $g$ -

${ }^{\dagger}$ To whom correspondence should be addressed (Tel: +82-2-2290-0494, Fax: +82-2-2297-4941, E-mail: bckim@hanyang.ac.kr). 
PVAC copolymer was prepared as follows. A $8 \mathrm{~g}$ cellulose were immersed in $200 \mathrm{~mL}$ distilled water for $30 \mathrm{~min}$, and $7 \mathrm{wt} \%$ CAN solution in VAC monomer was added to the cellulose-immersed aqueous system. After stirring at $35^{\circ} \mathrm{C}$ the reactant was filtered, washed with distilled water and acetone several times to remove the unreacted monomer and pure PVAC. To examine the effects of reaction time on grafting, the content of VAC monomer was fixed at $25 \mathrm{~g}$ corresponding to $3.13 \mathrm{~g} / \mathrm{g}$ (cellulose/VAC) and reaction time varied from 0.5 to $24 \mathrm{~h}$. To examine the effects of content of VAC monomer on grafting, reaction time was fixed at $3 \mathrm{~h}$ and the content of VAC monomer varied from 5 to $25 \mathrm{~g}$ corresponding to $0.63,1.25,1.88,2.50$, and $3.13 \mathrm{~g} / \mathrm{g}$ (VAC/cellulose). Grafting efficiency of VAC $\left(\% G_{\mathrm{VAC}}\right)$ in the graft copolymerization was calculated by eq 1 .

$$
\begin{aligned}
& \% G_{\mathrm{VAC}} \\
& =\frac{\text { weight of grafted sample }- \text { weight of original cellulose }}{\text { weight of original cellulose }} \\
& \quad \times 100
\end{aligned}
$$

The saponification of cellulose- $g$-PVAC copolymers was carried out as follows; $4 \mathrm{~g}$ copolymers were dissolved in $200 \mathrm{~mL}$ methanol at $5-10^{\circ} \mathrm{C}$ for $30 \mathrm{~min}$, and $40 \%$ solution of $\mathrm{NaOH}$ was added to the solution and stirred at $25-30^{\circ} \mathrm{C}$ for $5 \mathrm{~h}$. The reactant was filtered and washed with distilled water and acetone several times. After saponification, the content of grafted PVA $\left(\% G_{\mathrm{PVA}}\right)$ was calculated by eq 2 .

$$
\% G_{\mathrm{VA}}=\frac{\text { weight of saponified sample }}{\text { weight of original cellulose }} \times 100
$$

\section{Preparation of Lyocell Fibers Containing Cellulose-g- PVA Copolymers}

Pre-mixtures of cellulose and cellulose- $g$-PVA copolymers with different VA content were dissolved in NMMO monohydrate at $120^{\circ} \mathrm{C}$ under nitrogen purging. The composition of cellulose/NMMO monohydrate was fixed at $13 / 87$ by wt and copolymer and PG content were 5 and $0.3 \mathrm{wt} \%$ of cellulose, respectively. These solutions were dry jet-wet spun through the nozzle hole at $120^{\circ} \mathrm{C}$, whose diameter was $0.2 \mathrm{~mm}$. In dry jet-wet spinning, the air gap was $200 \mathrm{~mm}$ and extruding rate was $0.04 \mathrm{~g} \mathrm{~min}^{-1}$. Take-up speed was $20 \mathrm{~m} \mathrm{~min}^{-1}$ and distilled water was used for coagulation bath.

\section{Measurement of Physical Properties}

Fourier transform infrared(FT-IR) spectra of the copolymers were taken with a Nicolet Magna-IR 760 (U.S.A) at $400-4000 \mathrm{~cm}^{-1}$ and resolution of $4 \mathrm{~cm}^{-1}$. The samples were prepared as $\mathrm{KBr}$ pellets. Thermal properties of the copolymers were measured by TA Instruments differential scanning calorimeter (DSC) 2100 (U.S.A) at a heating rate of $10{ }^{\circ} \mathrm{Cmin}^{-1}$ under nitrogen purging. Crystal structure of the fibers was determined by wide angle X-ray diffractometer (WAXD) (MacScience M-18, Japan) equipped with Ni-filtered $\mathrm{Cu}-K \alpha$ radiation at $45 \mathrm{KV}$ at $200 \mathrm{~m} \AA$. Fibrillation was measured with a Brason sonifer $450 .{ }^{9}$ Ten filaments of $15 \mathrm{~mm}$ samples were immersed in distilled water at $20^{\circ} \mathrm{C}$ for $10 \mathrm{~min}$. Strong sonic wave was radiated onto the fiber surface for $15 \mathrm{~min}$. Fiber morphology was observed by scanning electron microscopy (SEM ABT SX-40A, Japan) and optical microscope (Leica Co., Germany). The fibrillation index was calculated by eq 3 , using optical micrographs of fibrillated fibers.

$$
\text { Fibrillation Index }=\frac{\sum_{L} l}{L}
$$

where, $l$ and $L$ are fibril and fiber length, respectively.

\section{RESULTS AND DISCUSSION}

\section{Preparation of Cellulose-g-PVA Copolymers}

Figure $1 \mathrm{a}$ and $1 \mathrm{~b}$ show the effects of reaction time
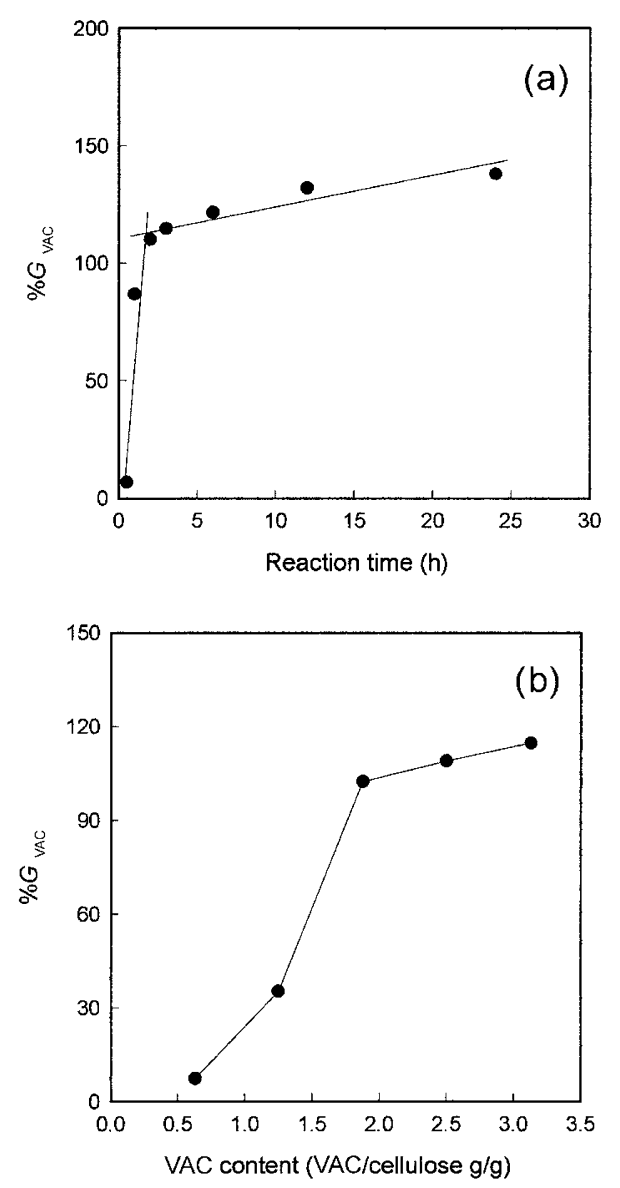

Figure 1. Variation of $\% G_{\mathrm{VAC}}$ during graft copolymerization of cellulose and VAC monomer; (a) reaction time and (b) VAC content. 
Table I. Characteristic features of cellulose-g-PVA copolymers

\begin{tabular}{|c|c|c|c|c|}
\hline \multirow[b]{2}{*}{$\begin{array}{l}\text { Sample } \\
\text { code }\end{array}$} & \multicolumn{2}{|c|}{ Preparation conditions } & \multirow[b]{2}{*}{$\% G_{\mathrm{VAC}}$} & \multirow[b]{2}{*}{$\% G_{\mathrm{VA}}$} \\
\hline & $\begin{array}{l}\text { Reaction time } \\
\text { (h) }\end{array}$ & $\begin{array}{c}\text { VAC content } \\
(\mathrm{g} / \mathrm{g})\end{array}$ & & \\
\hline VA $13 \%$ & 3 & 1.25 & 35.25 & 12.93 \\
\hline VA $36 \%$ & 3 & 3.13 & 114.75 & 36.26 \\
\hline VA $47 \%$ & 2 & 3.13 & 110.13 & 46.76 \\
\hline
\end{tabular}
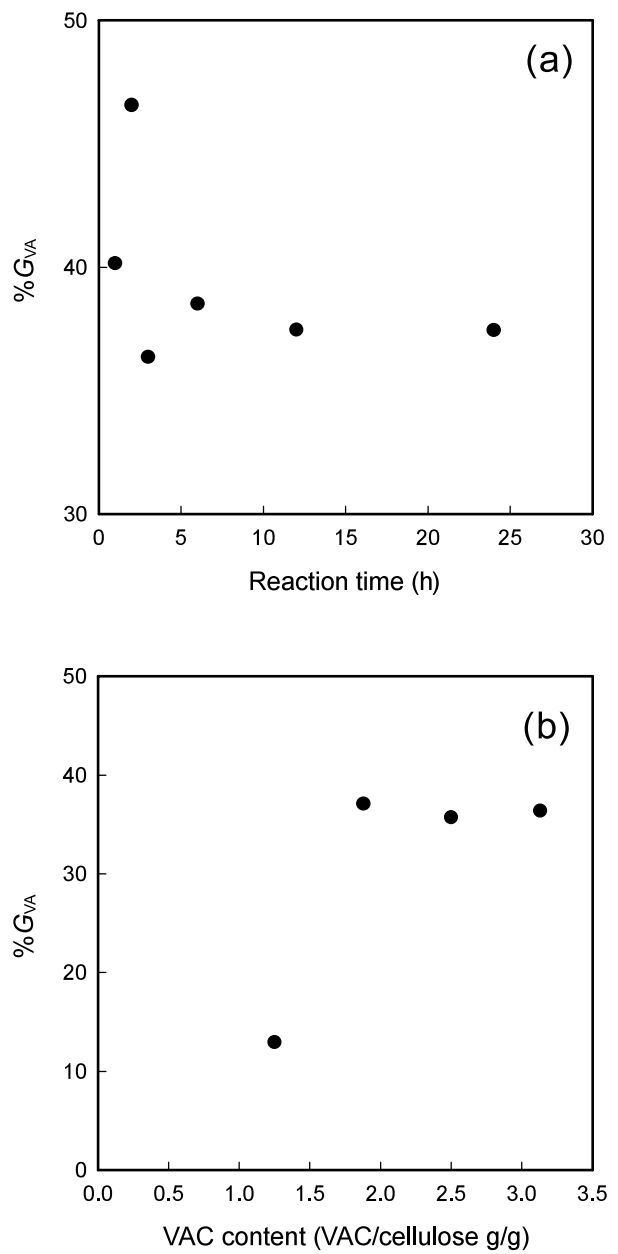

Figure 2. Variation of $\% G_{\mathrm{VA}}$ with saponification; (a) reaction time and (b) VAC content.

and monomer content on graft copolymerization of VAC onto cellulose. $\% G_{\mathrm{VAC}}$ increased sharply with reaction time and VAC concentration up to $2 \mathrm{~h}$ and $1.88 \mathrm{~g} / \mathrm{g}$ (VAC/cellulose), respectively, and then decreased because the rate of graft-copolymerization is kinetically slower than the rate of self-polymerization of VAC monomer. Steric hindrance of grafted polyvinyl acetate (PVAC) thus makes the accessibility of VAC monomer to cellulose backbone more difficult. ${ }^{17,18}$ This agrees with the cellulose-grafted-methyl methacrylate and PVA-grafted-methyl acrylate copolymer systems. ${ }^{17,19}$

The saponificated copolymers showed VA content from 13 to $47 \mathrm{wt} \%$ as shown in Figure 2. $\% G_{\mathrm{VA}}$ became almost constant at over $2 \mathrm{~h}$ reaction time (Fig-

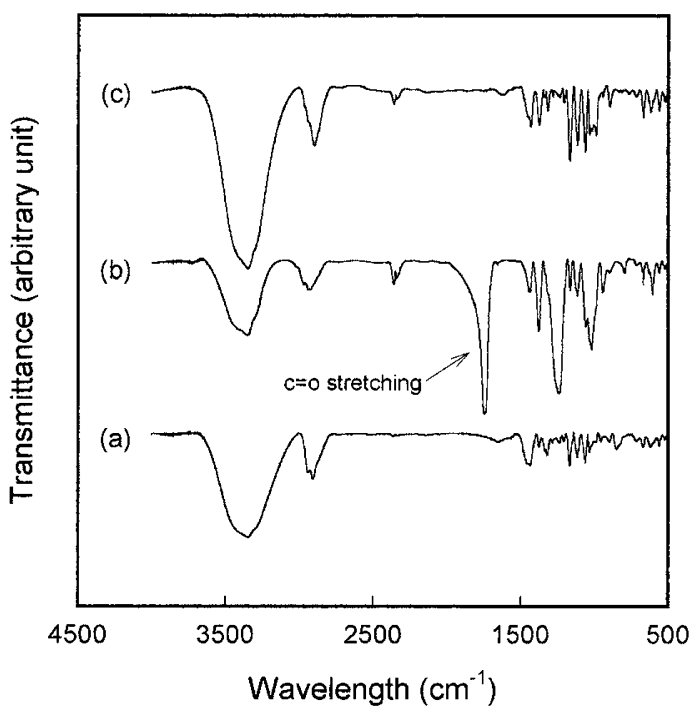

Figure 3. FT-IR spectra of cellulose (a), cellulose-g-VAC copolymer (b), and cellulose-g-VA copolymer (c).

ure $2 \mathrm{a}$ ) or $1.88 \mathrm{~g} / \mathrm{g}$ VAC content (Figure $2 \mathrm{~b}$ ), as expected from $G_{\mathrm{VAC}}$ in Figure 1. Consequently, cellulose$g$-PVA copolymers with VA content $13-47 \mathrm{wt} \%$ should be obtained by control of preparation conditions. The characteristic features of the copolymers in this study are summarized in Table I.

FT-IR spectra of cellulose, cellulose- $g$-PVAC and cellulose- $g$-PVA copolymers are shown in Figure 3. The cellulose- $g$-PVAC copolymer gave - $\mathrm{COO}-$ stretching band at $1730 \mathrm{~cm}^{-1}$, which was not observed in the spectrum of cellulose-g-PVA copolymer, indicating that the VAC group is converted to the VA group by saponification.

Figure 4 shows the melting behavior of the VA $47 \mathrm{wt} \%$ copolymer and cellulose/PVA blend whose ratio is similar to copolymer composition. The blend exhibited a melting peak of PVA. In the case of the copolymer, the melting peak was not observed, suggesting that PVA-grafted cellulose cannot crystallize because the alcohol groups of PVA make hydrogen bonds with cellulose backbones.

Preparation of Lyocell Fibers Containing Cellulose-gPVA Copolymers

Figure 5 shows WAXD patterns of lyocell fibers and fibers containing cellulose- $g$-PVA copolymers with different VA content. The samples showed diffraction 
Table II. Effects of VA on mechanical properties and birefringence

\begin{tabular}{ccccc}
\hline \multirow{2}{*}{ Sample } & \multicolumn{3}{c}{ Mechanical properties } & \\
\cline { 2 - 4 } & $\begin{array}{c}\text { Stress at break } \\
(\mathrm{g} / \mathrm{d})\end{array}$ & $\begin{array}{c}\text { Strain at break } \\
(\%)\end{array}$ & $\begin{array}{c}\text { Young's modulus } \\
(\mathrm{g} / \mathrm{d})\end{array}$ & Birefringence \\
\hline VA 0 wt $\%$ & 2.51 & 3.6 & 183 & 3.52 \\
VA 13 wt $\%$ & 2.57 & 4.1 & 210 & 2.98 \\
VA 36 wt $\%$ & 2.45 & 4.5 & 207 & 2.13 \\
VA 47 wt $\%$ & 2.54 & 4.4 & 209 & 2.05 \\
\hline
\end{tabular}

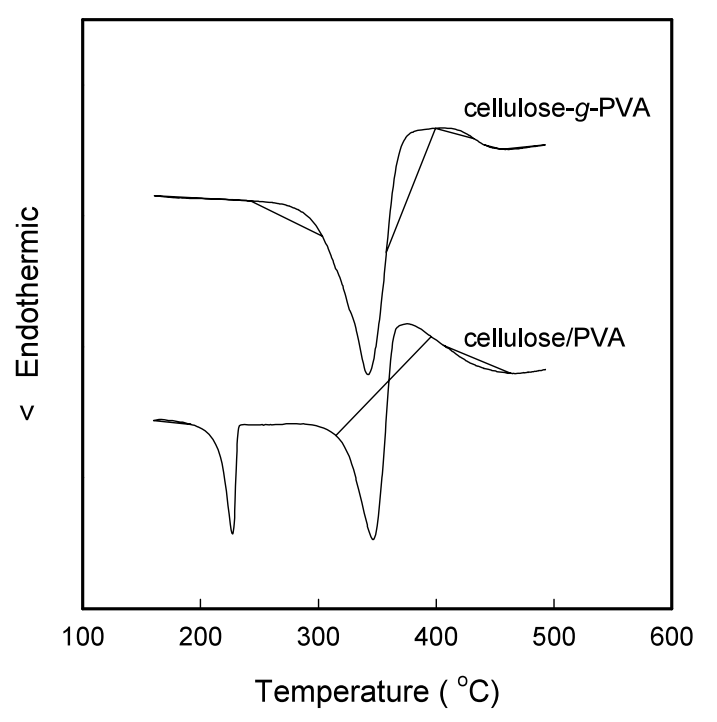

Figure 4. Melting behavior of VA $47 \mathrm{wt} \%$ copolymer and cellulose/PVA blend.

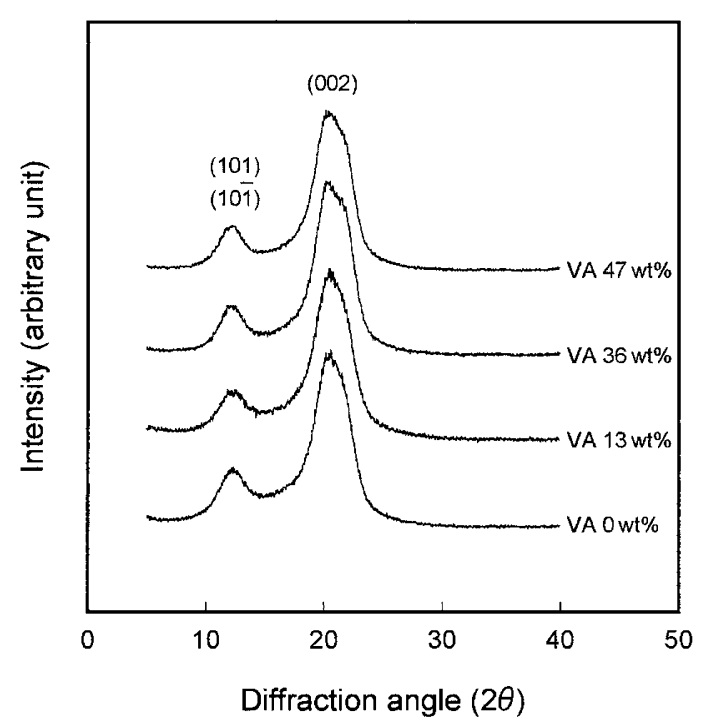

Figure 5. WAXD patterns of lyocell fibers and fibers containing cellulose- $g$-PVA copolymers.
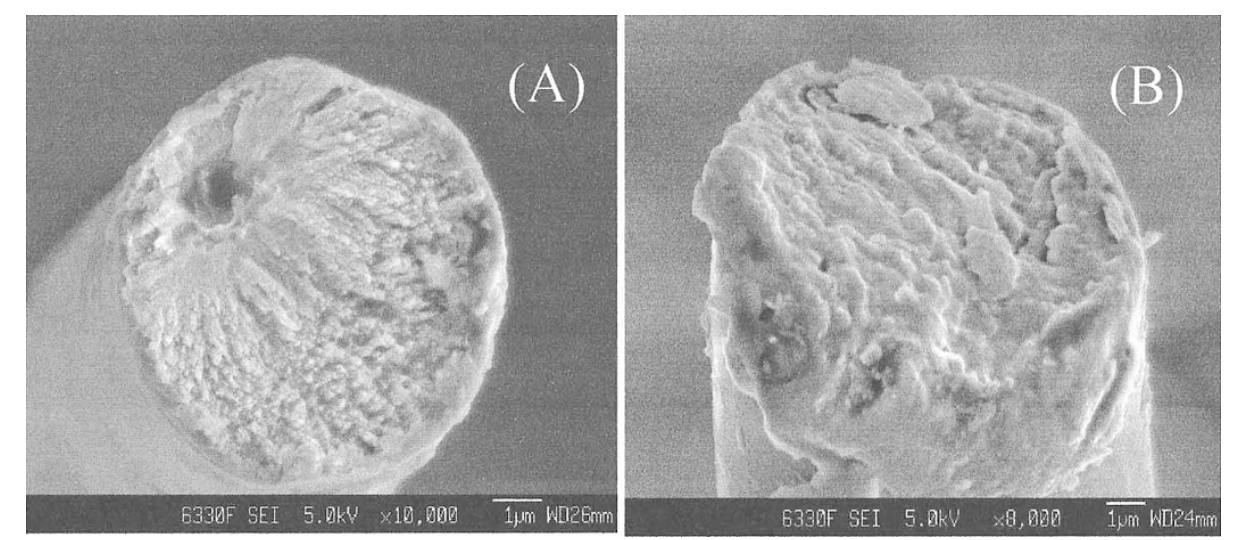

Figure 6. SEM micrographs of a fractured cross-section; (a) lyocell fiber and (b) lyocell fiber containing VA 47 wt $\%$ copolymer.

planes of (101), (101), and (002) at diffraction angles of $2 \theta=12.2^{\circ}$ and $21.5^{\circ}$, respectively. ${ }^{20}$ The copolymer thus has the structure of cellulose II and copolymer addition does not affect the crystal structure of lyocell fibers irrespective of VA content.

The effects of VA content on the mechanical properties and birefringence of lyocell fibers are summarized in Table II. As VA increases, strain at break and Young's modulus increases slightly, but stress at break remains almost constant. At a given copolymer content $(5 \mathrm{wt} \%)$, VA content of copolymer has little effect on mechanical properties. However, birefringence decreases with VA. The copolymer thus disrupts the orientation of cellulose chains because the VA group of copolymer makes hydrogen bonds with the cellulose chain.

The reduction of orientation by copolymers is reconfirmed by fractured morphology of the fibers. A crosssection of a fractured fiber is shown in Figure 6. The lyocell fiber shows a well-developed microfibril structure as a result of orientation. For fibers containing VA $47 \mathrm{wt} \%$ copolymer, however, no microfibril structure was observed. 

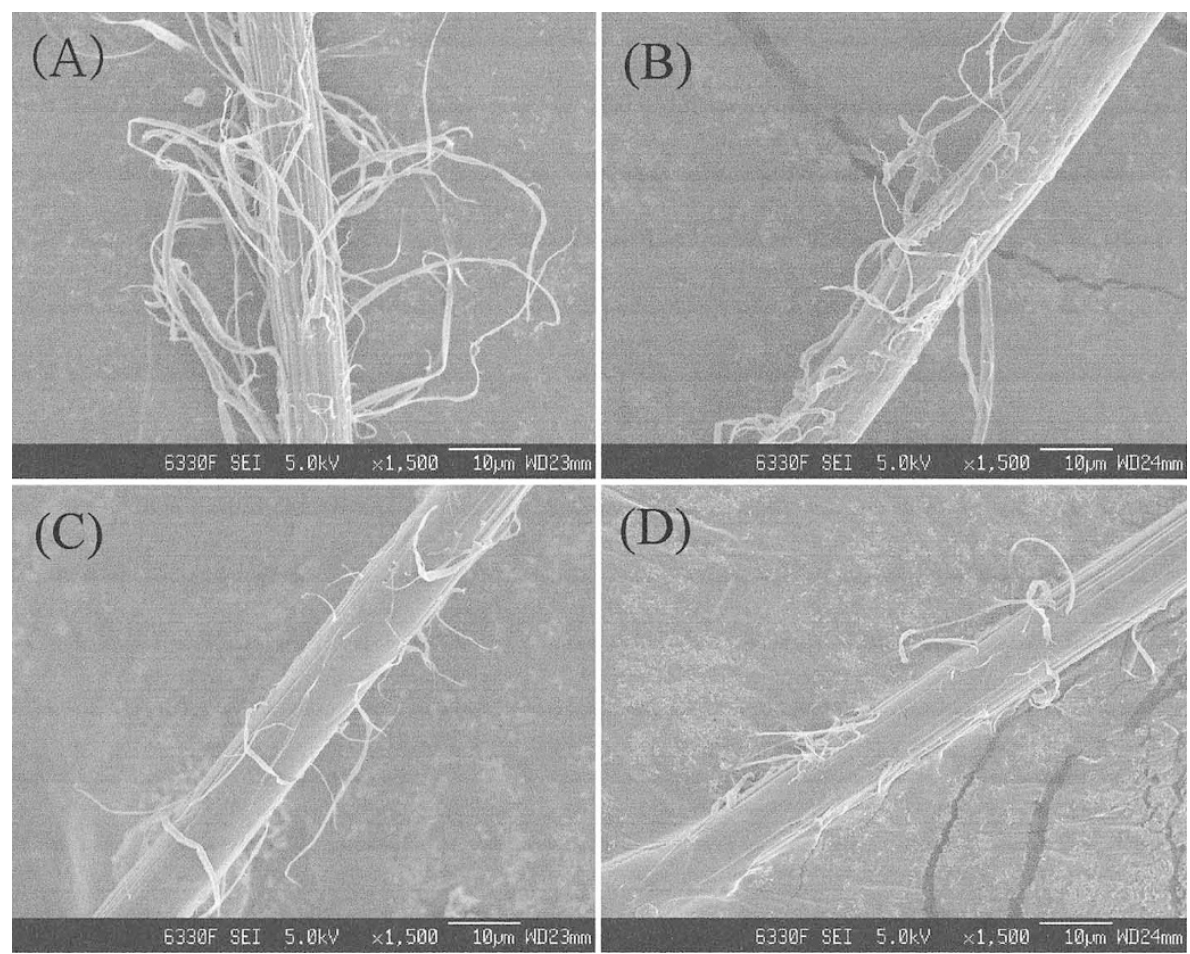

Figure 7. Effects of VA content on the fibrillation of lyocell fibers measured by SEM;

(a) VA $0 \mathrm{wt} \%$, (b) VA $13 \mathrm{wt} \%$, (c) VA $36 \mathrm{wt} \%$, and (d) VA $47 \mathrm{wt} \%$.

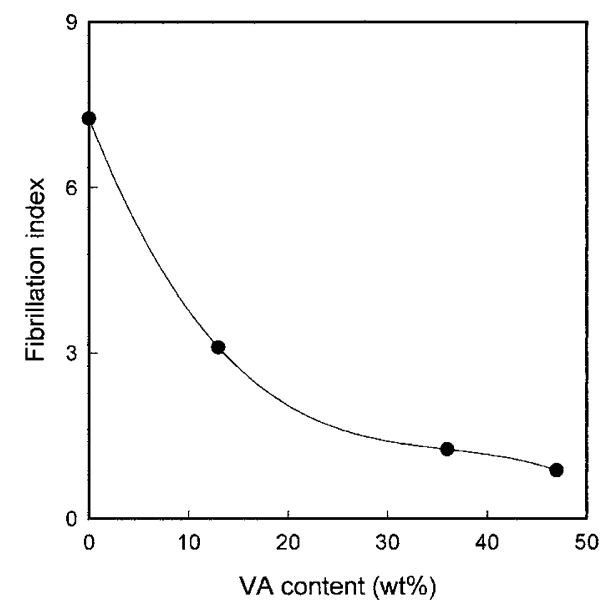

Figure 8. Variation of fibrillation index with VA content.

The effect of VA on fibrillation of lyocell fibers is shown in Figure 7. Fibers containing the copolymers had less fibrillation than lyocell fibers and this was more noticeable at higher VA content. As shown in Figure 8, fibrillation index corresponding to fibril length decreases with VA content owing to hydrogen bonds between cellulose and the VA group. Hydrogen bonds thus improve lateral cohesion of crystal regions because the copolymer acts as a cross-linking agent. VA content of the copolymers thus has decisive effect on the fibrillation of lyocell fibers and suppressed fibrillation of the lyocell fiber by cellulose- $g$-PVA may be due to increase in hydrogen bonds and decreased orientation.

\section{CONCLUSION}

The effects of adding cellulose- $g$-PVA copolymers of various VA content to lyocell fibers on the fibrillation of lyocell fibers were found to be decisive. Increase in VA leads to less fibrillation due to the formation of hydrogen bonds. Control of the content and chemical composition of the copolymer may help produce lyocell fibers with less fibrillation and good mechanical properties.

\section{REFERENCES}

1. G. Raven, Int. Fibers J., 6, 10 (1993).

2. W. S. Lee and S. M. Jo, Chem. Fibers Int., 49(3), 46 (1999).

3. W. Berger, Lenzinger Berichte, 9, 11 (1994).

4. D. Eichinger and M. Eibl, Techtextil, May, 13 (1997).

5. M. E. Hall, A. R. Horrocks, and H. Seddon, Polym. Degradation Stability, 64, 505 (1999).

6. S. Davies, Textile Outlook Int., 44, 8 (1996).

7. P. G. Bullio, Am. Textiles Int., 21(9), FW16 (1992).

8. D. Loubinoux and S. Chaunis, Textile Res. J., 57, 61 (1987).

9. S. A. Mortimer and A. A. Péguy, J. Appl. Polym. Sci., 60, 305 (1996).

10. H. Nemec, Lenzinger Berichte, 9, 69 (1994).

11. J. Lenz and L. Schurz, Cellul. Chem. Technol., 24, 679 (1990).

12. J. Lenz, J. Schurz, and E. Wrentschur, Das Papier, 42, 683 (1988).

13. J. Lenz, J. Schurz, and E. Wrentschur, Colloid Polym. Sci., 271, 460 (1993).

14. G. Buschle-Diller, S. H. Zeronian, N. Pan, and M. Y. Yoon, 
K. Y. Lim, Y. J. SEONG, and B. C. KIM

Textile. Res. J., 64, 270 (1994).

15. J. M. Taylor, Courtaulds, Eur. Patent, 538,977 A1 (Apr, 28, 1993).

16. J. M. Taylor, Courtaulds, U. S. Patent, 5,310,424 (Apr. 6, 1992).

17. P. Choedhury and C. M. Pal, Eur. Polym. J., 35, 2207 (1999).

18. E. A. Abdel-Razik, J. Photochem. Photobiol., A: Chem., 107,
271 (1997).

19. I. Sakurada, "Polyvinyl Alcohol Fibers", Marcel Dekker Inc., New York, N.Y., 1985, chapt. 2.

20. R. A. Young and R. M. Rowell, "Cellulose Structure, Modification and Hydrolysis", John Wiley \& Sons, Inc., New York, N.Y., 1986, pp 27-40. 